\title{
De las Malvinas al corralito: Entrevista con Sergio Balardini
}

\section{Sergio Balardini ${ }^{5}$ entrevistado por Carles Feixa ${ }^{6}$}

Resumen (analítico): Sergio Balardini es uno de los pioneros de la «juvenología» argentina y latinoamericana. El texto se basa en una conversación mantenida por los autores en Buenos Aires en agosto de 2017 y recorre las tres vidas del protagonista: su biografía como joven, como militante político y como investigador. Empieza con sus recuerdos de adolescencia y juventud en la Argentina de los años setenta; sigue con reflexiones sobre la guerra de las Malvinas de 1982 como «marca generacional»; recorre su militancia política en las filas socialistas en la década de los ochenta y noventa, durante la transición a la democracia, y se centra en su descubrimiento de la juvenología y su trabajo por institucionalizarla en instituciones como Flacso, el GT Juventud de Clacso y la Fundación Friedrich Ebert, con la crisis político-económica que condujo al corralito de 2001 como parteaguas.

Palabras clave: Juventud, generación, movimientos juveniles, políticas de juventud (Tesauro de Ciencias Sociales de la Unesco).

Palabras clave autores: Juventud, generación, Argentina, políticas, rock.

\footnotetext{
5 Investigador de la Fundación Friedrich Ebert, Argentina. Correo electrónico: sergio.balardini@gmail.com E1 artículo se basa en la transcripción de la entrevista realizada en agosto de 2017. Ha sido revisada por Sergio Balardini y editada por Carles Feixa.

6 Catedrático de Antropología Social en la Universitat Pompeu Fabra (Cataluña, España). Correo electrónico: carles.feixa@upf.edu
} 


\section{From the "Malvinas" to the "corralito": an interview wirh Sergio Balardini}

Abstract (analytical): Sergio Balardini is one of the pioneers of "youthology" in Argentina and Latin America. The text is based on a conversation held by the authors in Buenos Aires in August 2017 and covers the three lives of the protagonist: his biography as a young man, as a political militant and as a researcher. It begins with its memories of adolescence and youth in the Argentina of the 70 , continues with reflections on the 1982 "Malvinas" war as a "generational brand", runs through its political militancy in the socialist ranks in the 8 os and 9os, during the transition to democracy, and focuses on his discovery of youth and his work to institutionalize it in institutions such as Flacso, the Clacso Youth GT and the Friedrich Ebert Foundation, with the political-economic crisis that led to the "Corralito" of 2001 as watershed. Keywords: Youth, generations, youth movements, youth policies (Social Sciences Unesco Tesaurus).

Autors keywords: Youth, generation, Argentina, politics, rock.

\section{Das Malvinas para o corralito: Entrevista a Sergio Balardini}

Resumo (analítico): Sergio Balardini é um dos pioneiros da "juvenologia" na Argentina e na América Latina. O texto é baseado em uma conversa realizada pelos autores em Buenos Aires em agosto de 2017 e abrange as três vidas do protagonista: sua biografia quando jovem, como militante político e como pesquisador. Começa com suas memórias de adolescência e juventude na Argentina dos anos 7o, continua com reflexões sobre a guerra das Malvinas em 1982 como uma "marca geracional", atravessa sua militância política nas fileiras socialistas nas décadas de 8 o e 9o, durante a transição para a democracia, e se concentra em sua descoberta da juventude e seu trabalho para institucionalizá-la em instituições como a Flacso, o GT Clacso e a Fundação Friedrich Ebert, com a crise político-econômica que levou ao Corralito de 2001 como divisor de águas.

Palavras-chave: Juventude, geração, movimentos juvenis, políticas da juventude.

Palavras-chave autores: Juventud, geração, Argentina, política, rock (Tesaurus de Ciencias Sociais da Unesco). 
Este artículo está dedicado a la memoria de René Bendit (1944-2018)

\section{Introducción}

Conocí por primera vez a Sergio Balardini en 1997, durante un encuentro organizado por José Antonio Pérez-Islas en Ixtapan de la Sal (México) para preparar el marco teórico-metodológico de la Encuesta Nacional de Juventud de México, en el que también participó la flor y nata de la «juvenología» latinoamericana, incluyendo a Rossana Reguillo, José Manuel Valenzuela, Maritza Urteaga, Ernesto Rodríguez, Carlos Mario Perea, entre otros. ${ }^{7}$ Enseguida congeniamos por nuestro interés compartido por el rock, por mayo del 68 y por las ciberculturas. En 1999 le invité a unas jornadas que organicé en la Universidad de Lleida sobre los jóvenes en Europa y América Latina, en el que también participaron Lynne Chisholm, José A. Pérez Islas, José Manuel Valenzuela y Alonso Salazar. Balardini presentó una interesante ponencia sobre el 68 argentino, que sucedió un año después (el «cordobazo» de 1969), así como su antecedente histórico en el movimiento de la reforma universitaria de Córdoba de 1918, posteriormente publicado como capítulo de libros editados por mí en catalán y castellano (Feixa, 20oo; Feixa et al., 2002; Balardini, 2000, 2002).

En 2002 organizamos conjuntamente un encuentro sobre la juventud y la sociedad de la información, que pretendía ser un lugar de confluencia entre juvenólogos latinoamericanos y europeos (Sergio coordinaba entonces el GT de Clacso sobre juventud), en el que también participaron dos personas claves en esta confluencia, tristemente desaparecidas: René Bendit (investigador del Instituto Alemán de la Juventud) y Lynne Chisholm (presidenta del RC34 Sociology of Youth). De ese encuentro surgió el proyecto de publicar una historia comparada de la juventud en América Latina - que no existía-, lo que pudimos realizar al cabo del tiempo, primero en portugués (Caccia-Bava, González, \& Feixa, 2004) y luego en castellano (González \& Feixa, 2016), encargándose Sergio del capítulo sobre Argentina (Balardini, 2004, 2016). En 2001 fui yo quien le visité en Flacso - donde Sergio trabajaba entonces-durante dos semanas intensas en las que pude conocer de primera mano sus trabajos y los de sus colegas en Argentina. Recuerdo bien el clima algo depresivo en lo económico y en lo político: una semana después de regresar a Cataluña estalló el corralito. Desde entonces volvimos a coincidir en todas mis estancias en Buenos Aires, aunque Sergio había dejado de coordinar el área de juventud en

7 Para una evocación de ese encuentro y una discusión crítica sobre el concepto de juvenología latinoamericana e iberoamericana, véase Feixa y Urteaga (2019). 
Flacso y había comenzado a trabajar para una fundación alemana vinculada a la socialdemocracia, en varios proyectos de cooperación juvenil. ${ }^{8}$

En 2017 llevé a cabo una estancia de dos meses en la Universidad Tres de Febrero de Buenos Aires, en el marco del proyecto europeo CRIC, y me propuse entrevistar a una selección de «juvenólogos» argentinos, tanto algunos de los pioneros como representantes las nuevas generaciones de investigadores. ${ }^{9}$ La última de la docena de entrevistas que realicé en Argentina fue la de Sergio Balardini. Nos encontramos en la sede de Flacso y comimos juntos en un restaurante cercano, donde puse mi grabadora a funcionar. Pese a lo ruidoso del ambiente y a lo apretado del tiempo, pude recoger lo principal de su trayectoria como joven y como investigador, muy vinculada a la historia de Argentina desde el final de la dictadura a la transición democrática. Del diálogo surge un mapa de los estudios sobre juventud en América Latina, pero también sugerentes reflexiones sobre la continuidad y el cambio generacional.

\section{Las Malvinas como marca generacional}

Carles Feixa (C. F.): Para empezar, Sergio, me gustaría pedirte si puedes presentarte; ¿en qué año naciste? 10

Sergio Balardini (S. B.): Nací el 29 de enero de 1960 y desde mediados de los años sesenta a mediados de los ochenta, mi adolescencia y juventud estuvo marcada por la dictadura en Argentina, con algún intervalo de retorno a la democracia. ¿Por qué abordo los temas de juventud? Por varias razones, no hay una sola causa; pero podría partir de una motivación personal. Siempre sentí, desde muy pequeño, una cierta incomodidad en el vínculo entre los adultos y los jóvenes; un malestar, te diría, cultural o sociocultural sin haber desarrollado aún conceptualizaciones intelectuales, quizás, de orden prepolítico.

Mi primer recuerdo de esa incomodidad es de cuando estaba en primer grado de la escuela primaria y tuve una disputa con otro compañero; teníamos seis años, éramos muy chicos.

\footnotetext{
8 La Fundación Friedrich Ebert.

9 Las entrevistas forman parte del proyecto La juventud de los juvenólogos (Juju), que llevamos a cabo conjuntamente con Maritza Urteaga, y en el que pretendíamos recuperar las historias de vida de algunos de los principales investigadores en juventud del subcontinente. Hasta ahora se han publicado las entrevistas a Néstor García Canclini (Urteaga \& García-Canclini, 2007), Jesús Martín-Barbero (Feixa \& Martín-Barbero, 2008), Rossana Reguillo (Feixa, Ballesté, \& Reguillo, 2018) y José Antonio Pérez-Islas (Urteaga \& Pérez-Islas, 2019).

${ }^{10}$ Hemos optado por suprimir la mayor parte de las preguntas para reforzar la coherencia del discurso del entrevistado (N. del A.).
} 
En esa ocasión, la maestra no estaba en el aula, y, en medio de la puja, quedé atrapado detrás de la puerta de entrada; cuando intento salir, sin querer, golpeo a la maestra que estaba ingresando. ¿Qué hace la maestra? Me sanciona automáticamente sin darme la posibilidad de decir nada. No me da derecho a defensa. En esa situación soy un objeto de sus decisiones. Esa circunstancia me generó una enorme indignación, porque no tuve posibilidad de decir qué había pasado, ni presentar mis argumentos. Ese hecho de dominación por parte de un adulto me lastimó y me pareció muy injusto y, ahora diría en términos políticos, un abuso de poder.

Otro hecho que me marcó, ya en mi juventud, fue cuando presté el servicio militar, en 1979 en plena dictadura. Era un maltrato diario no solo sobre mí, sino también sobre todos mis compañeros soldados. Recuerdo una vez que la pasamos muy mal físicamente y un compañero me dice: «Podrán dominar nuestros cuerpos, pero nuestras cabezas siguen libres». El abuso, el maltrato y la pérdida de libertad provenían de una institución de adultos en la que quienes sufríamos éramos jóvenes. Aquella fue otra experiencia fuerte en mi vida en que la cuestión generacional me salta a la vista como conflicto.

Un tercer momento se produjo con la Guerra de Las Malvinas, año 1982. Mi cohorte como soldado estuvo a punto de ser convocada. Se llamó a servicio a la anterior; y, si la guerra continuaba un tiempo más, le tocaba ir a la mía. Éramos todos muy jóvenes. Imagínate el impacto de la guerra, las noticias, la tensión que me causaba esa situación; y, al mismo tiempo, una pregunta que continúa hasta hoy: ¿por qué una sociedad envía a la guerra a sus jóvenes y no a sus adultos? Envían a chicos de 18 y 19 años a una guerra. ¿Por qué no van los que tienen entre 450 50 años? No me satisface la respuesta de que los cuerpos más jóvenes resisten más; no es esa la razón por la que las sociedades envían a los jóvenes a la guerra. ¿Qué sentidos hay detrás de que a las guerras van los jóvenes, a la muerte van los jóvenes y, en este caso, jóvenes ya maltratados por la dictadura, reprimidos, a los que legalmente no se les permitía hacer cosas menores, pero que sí podían ir a defender al país para ser muertos o matar en su nombre? Algo estaba mal. Todas esas cosas jugaban en mi cabeza. Más tarde sabríamos que la represión de la dictadura, entre 1976 y 1982, se llevó la vida de miles de jóvenes; los organismos de derechos humanos hablan de 30 mil. Aproximadamente murieron en combate entre 700 u 800 jóvenes argentinos en la guerra de las Malvinas. Con el tiempo serán más del doble, sumando exsoldados que, en los años posteriores, se quitaron la vida. Una marca generacional. 


\section{Del rock a la política}

Pero unos años antes de las Malvinas, a fines de los años 7o durante la dictadura, me había volcado hacia el rock con intensidad porque, de alguna manera, era el espacio donde, aún con todas las restricciones, existían ciertas libertades; fuese por las letras, porque la música te convocaba, porque en algún pequeño lugarcito otros sentían algo parecido a vos en plena dictadura. Sentimiento que, poco a poco, fue creciendo y construyendo una suerte de «nosotros» del rock. Y, aunque en sus comienzos fue una movida más pequeña, había algo de identidades que necesitaban señas de libertad. En ese tiempo encontré en el espacio del rock la posibilidad de iniciar una nueva reflexión intelectual. En aquel entonces todavía estudiaba ingeniería, pero empecé a dedicar buena parte de mi tiempo a temas de filosofía, sociología y psicología (que siempre fueron motivo de mi interés), alentado por una revista «de rock» 1lamada Expreso imaginario, que ofrecía notas y debates sobre contraculturas, los poetas beat (Kerouac, Ginsberg, Ferlinghetti), entrevistas a tipos como el poeta y ecólogo Gary Snyder y otros temas que nadie debatía: aborígenes, medio ambiente, poesía, cine y teatro alternativo, hasta una «guía para habitar el planeta Tierra». Y su correo de lectores, de alguna manera, nos hermanaba a muchos. No era una revista solo de rock (el rock era un aspecto), sino de una perspectiva cultural alternativa y era la única revista que abordaba estos temas. También era asiduo oyente de los programas de radio y lector de los escritos de Miguel Grinberg, poeta, ecólogo e ideólogo contracultural del rock local.

En tiempos de dictadura, cuando aflojó un poco la represión, empezaron a surgir muchas revistas subterráneas, alternativas, todas hermanas menores del Expreso. Y estas revistas las hacíamos jóvenes, que teníamos 18, 17, 16 años, y se entregaban a mano en las filas de los conciertos de rock. Vos sabías que había un concierto e ibas a vender las revistas al valor del papel o las entregabas gratis si alguien se mostraba interesado y no tenía dinero, algo muy usual. Participé de algunas de esas revistas alternativas y contraculturales que entonces tenían la peculiaridad de ser hechas por los mismos sujetos que consumíamos el mundo rock.

Algunos jóvenes producían teatro alternativo, otros producían música rock y nosotros hacíamos revistas alternativas. Muchas de las cosas que hoy se discuten como novedad tienen vínculos muy directos con la experiencia del mundo del rock de aquel entonces, de los tiempos de la dictadura. Las autoproducciones, incluso el fanzine del que ahora se habla tanto, son experiencias de aquella época, de gente que producía sus propios discos a partir de avisar su intención de realizarlos e invitar a comprarlos antes de que existieran. Entonces, la gente pagaba por adelantado y después se producía el disco y se le enviaba. Hoy le llamamos crowdfunding. 
Otra modalidad, era juntar distintas hojas que cada quien aportaba con su propia creación, se abrochaban artesanalmente y salía una revista colectiva. Claro, en tiempos de redes, es más fácil hacerlo; en aquel entonces era el boca a boca y juntarse en la plaza o el parque.

En esa época, a principios de los ochenta, las cosas estaban en un momento de cierta sensibilidad creativa y solidaridad generacional; al mismo tiempo, yo ya tenía mis intereses políticos. Así es que me involucro en la política en el año 1980, con 20 años, bajo dictadura. El Partido Socialista Auténtico al que me acerqué tenía sus círculos de formación (como todo partido de izquierda), y yo andaba con el «manifiesto» de aquí para allá, disfrazado de otro libro, con tapas cambiadas; pero, hoy pienso, arriesgando bastante por circular con ese tipo de materiales. En esa época, por un lado, leía prensa partidaria, materiales clásicos y, por otro, el Expreso imaginario e iba a cuanto recital de rock se me aparecía. Luego, con la guerra de las Malvinas en 1982, la situación se hizo más compleja y dramática en términos generacionales. Al terminar, con la derrota, hubo una fuerte movilización contra los militares; de algún modo comienza el fin de la dictadura y, con los meses siguientes, estalla el tema de los derechos humanos, los desaparecidos. Y ahí empiezo a militar más orgánicamente, en lo que fue el denominado Partido Intransigente. Una izquierda más renovada, de tendencia nacional popular. Ya no era el marxismo clásico; era una propuesta política en la que el tema de los derechos humanos convocó a militar a muchos jóvenes.

Por ese entonces, tuve un accidente que me llevó a tener tres meningitis en pocos meses. La primera, en el año 1982, fue grave y estuve internado varios días inconsciente. Cuando desperté, recuerdo que venían médicos a observarme y alguno me dijo: «vos volviste a vivir; nadie daba un peso por vos». Entonces, sentí que tenía una segunda oportunidad y empecé a valorar diferente algunas cosas. Me pregunté qué es lo que realmente quería, qué tenía que revisar, qué cosas no y qué cosas sí. Dejé la ingeniería y empecé a estudiar psicología. Seguí mi vida, pero debí enfrentar el hecho de que tenía una fisura en la base de cráneo que, por vía nasal, era el canal de acceso de gérmenes y que había que sellarla para evitar nuevas meningitis. En el año 84 tuve una cirugía complicada - que por suerte fue exitosa - en la que me cerraron la fisura. Digamos que se me fueron algunos meses resolviendo este tema. Recuperado, me reintegré a la vida militante y, en los años 1985 y 1986, fui secretario de formación política de la Juventud Intransigente (JI) de la capital. También conduje el centro de estudiantes de mi universidad.

Por la misma época, para mantenerme, trabajaba en escuelas secundarias (una de clase media y otra técnica de sectores más populares) en las que tenía vínculos todo el tiempo con adolescentes. Yo, a la vez, era joven. Tal vez en parte por los ámbitos en que me movía, y en parte por mis intereses, fui encargado - junto con otros pocos militantes de la JI- del desar- 
rollo de un programa orientado a la juventud, que en propuestas fue muy innovador, porque hasta ese momento lo que hacía la juventud política era replicar los temas de los adultos (la deuda externa, lo que sea). Entonces, se cuestionó cuáles eran los temas que tocaban más propiamente a los jóvenes. Y empezamos a hablar de otras cosas, empezamos a construir una agenda juvenil. Empezamos a hablar de empleo joven, de salud, sexualidad, drogas. Además, muchos veníamos cargados de un ambiente roquero. En el 89 sacamos El aguante, una revista bastante contracultural que tenía poco que ver con lo que hasta entonces se entendía como revista de una juventud política, la cual generó rechazo interno. Era una mirada nada tradicional en la política. Hicimos todo un proceso en el que empezamos a construir programáticas juveniles, una agenda juvenil para la juventud política, que no existía hasta entonces. No digo que fuésemos los únicos, pero fuimos entre los primeros que generaron esa diferencia, con mucha resistencia interna.

\section{De la militancia a la investigación}

En paralelo, y transcurrido un tiempo, terminé la carrera de psicología. Hay elecciones nacionales y, en 1989, Menem gana las elecciones. Como suele suceder, las cosas no son lineales y no imaginamos su deriva neoliberal. Pero en la capital, en un marco particular, el acuerdo de la JI con la Juventud Peronista nos lleva a que nos propongan participar de la Secretaría de la Juventud que había fundado la Juventud Radical dos años antes (en el 87). Así, fui designado - junto con otro compañero de la Juventud Intransigente- para integrarme a la Secretaría de la Juventud. En ese marco, propusimos un proyecto sobre algo que no existía: un instituto de investigaciones en temas de juventud y lo aceptaron. Ingreso al proyecto a partir de un acuerdo político, pero necesito formarme en el tema. Ahí se produce una coincidencia de intereses

notable: a los pocos meses de iniciada esa aventura, leo en el diario una pequeña noticia: Flacso va a ofrecer un seminario sobre temas de juventud y políticas para jóvenes, a cargo de un tal René Bendit. Se alinearon los planetas.

Desde la Secretaría decidimos ir; era la primera vez que leíamos sobre «política de juventud» como tema específico y ahí conocimos a René. Fue mi primer seminario sobre juventud y me abrió la cabeza a otro mundo, a las juventudes, a las culturas juveniles, a la política de juventud y a la posibilidad de dedicarme en serio a trabajar e investigar sobre esto. Además, descubrir que había gente que lo había hecho antes, aunque no localmente, sino en otras geografías. Empezamos a trabajar en eso alrededor de los años 1989 y 1990. El otro alineamiento de planetas es que en Flacso, quien invitó a René fue Cecilia Braslavsky, que estuvo a cargo en la Cepal de los estudios para el Año Internacional para la Juventud (1985). Ella, como directora 
de Flacso, estaba interesada en el tema de juventud. En su exilio en Alemania, conoció a René y lo trae para ver si lograba organizar algún grupo de estudios sobre juventud en Flacso. Asistieron, entre otras personas que hoy todavía trabajamos el tema o campos anexos, Ana Wortman (cultura), Mariela Macri (empleo) y Víctor Mekler (educación). Además, hay un punto en particular que genera una empatía entre Bendit y yo, sumamente relevante: ambos somos hinchas de Chacarita Juniors, un club de fútbol con una fuerte identidad, de la ciudad de San Martín cerca de donde vivo. ¡Tanto René como yo nacimos en San Martín! Cuando en el seminario hice un comentario sobre la hinchada de Chacarita, a René, que era muy fanático, se le iluminaron los ojos. Cuestiones de barrio que abrieron lugar a una fraternidad profunda.

René nos ayudó a armar y a pensar lo que estábamos haciendo en el área de juventud. Trae a Juan Sáenz, ${ }^{11}$ con quien tuvimos muy buena relación y nos ayudó mucho para pensar las políticas públicas de juventud. Estando en la Secretaría, le dijimos a René que queríamos hacer una encuesta de juventud en la ciudad, la cual, finalmente, hicimos en el año 1992. La preparamos desde un año y medio ante, con ayuda de Juan y de René. Fue la primera encuesta de juventud que se hizo en serio, con la dirección de estadística de la ciudad, capacitación en metodología, temas de juventud y articulación con la universidad; un proyecto importante, complejo (Balardini \& Hermo, 1997). De esa encuesta salieron muchas líneas de estudio y propuestas de política pública; y aprendimos mucho.

Mientras tanto, las contingencias de la política hicieron que la sostenibilidad del proyecto de investigaciones en la secretaría tambaleara y cambiara la gestión. A los nuevos funcionarios el tema les importa poco y damos la discusión al interior del área de juventud, para que el trabajo realizado no se perdiera. Se plantea realizar un convenio con Flacso para, con otros recursos, trabajar desde allí sobre la encuesta y lo que de ella derive. Hubo mucha discusión, pero terminaron por aceptar la propuesta. Conseguimos una razonable y respetuosa concesión de la Secretaría de la Juventud: que el equipo de la encuesta trabajara a partir de ese momento en Flacso. Ahí comienza a constituirse —en el 94- lo que luego sería el área de juventud de Flacso.

\section{De la investigación a la acción}

Estos son los antecedentes de mis intereses, de cómo llego a dedicarme al tema de la política de juventud y las juventudes, por la propia vida, el rock, la militancia, la academia, todo

\footnotetext{
${ }^{11}$ Historiador español, autor de una tesis doctoral sobre el Frente de Juventudes durante la dictadura franquista
} (Sáez, 1988) y funcionario del Instituto de la Juventud de España. 
junto y mezclado. No hay nada puro en eso, fue sumar experiencias, fue aprendizaje-error; fue en algún momento la buena estrella que, por algún lado, te toca y personas en particular que tuviste suerte de cruzarte. Aquellas que lo hicieron posible y me enseñaron, en principio fueron dos: René y Daniel Filmus, quien sucedió a Cecilia en la dirección de Flacso. Nos apoyaba y su presencia permitió un halo de legitimidad en la institución. También hay que decir que desde un primer momento comenzamos a discutir con René, en el buen sentido, porque nosotros aquí en Argentina teníamos tantísimas diferencias comparados con la realidad europea: la situación política, la cultura política y la cultura de gestión, que eran distancias insalvables para los modelos que se habían desarrollado en Europa. Sin embargo, esos modelos eran muy útiles para plantear la necesidad de construcción de una política de juventud bajo coordenadas y criterios locales. De allí a construir con otras herramientas, otras líneas argumentales, otros vínculos institucionales. Cuánto debate tuvimos con René sobre eso; sin René hubiera sido imposible. Pero, creo que también fue útil que los que estábamos acá siempre fuimos críticos.

Son muchos años y mucho artesanato, porque mucha cosa que hicimos fue artesanal y militante en el sentido de los esfuerzos personales y de equipo que tuvimos que hacer para instalar el tema y llevarlo adelante. Inaugurábamos un campo y los recursos eran menos que escasos. Otra característica es que nos abrimos a las organizaciones de jóvenes y casi que aceptábamos toda clase de propuestas y presentaciones; fue una etapa de apertura y aprendizaje. En algún momento, por los años 1995 y 1996, varias organizaciones juveniles crearon mesas de juventud y vinieron a Flacso a charlar con nosotros a ver si podíamos darles una mano. Actuamos como padrinos de la Mesa de concertación juvenil. Hacían sus reuniones en Flacso y escuchábamos lo que las distintas organizaciones planteaban. Para ellas era muy importante nuestro acompañamiento. Todos aprendíamos muchísimo. Les ayudamos a organizar ferias de proyectos juveniles, donde exponían su trabajo, su creatividad, acciones solidarias. Buscamos ofrecer una mirada sobre los jóvenes que los medios no mostraban. Esas alianzas con organizaciones de jóvenes en la ciudad derivaron también en vínculos con organizaciones a nivel nacional, las cuales tenían distintas dificultades. Tratábamos de generar un espacio que facilitara los encuentros e investigábamos sobre organizaciones juveniles. Para estos trabajos no había subsidios. Era todo muy artesanal; pero se hacía con muchas ganas y mucha voluntad. Fueron muy lindas experiencias y, en paralelo, desarrollábamos investigaciones de juventud en la ciudad.

Al mismo tiempo, desde el Estado empezaban a tantearnos, a ver quiénes éramos y a confiar en los saberes que íbamos construyendo. Así, a mediados de los 9o, nos invitan a orientarlos en el diseño de algunos programas y pudimos participar en esos diseños, como en el caso de la ciudad de Rosario. A nivel nacional, por esa misma época, y bajo el aval de la OIJ, nos invi- 
taron a evaluar las políticas de juventud del gobierno, que representó otro importante salto, porque nos vinculó a las políticas nacionales. Para esa tarea también fue clave haber cursado una maestría en administración pública, porque nos dotó de las herramientas de análisis necesarias. Recuerdo ese proceso: el esfuerzo para evaluar más allá de los papeles y discursos de los funcionarios y el desafío de escribir un documento que reflejara nuestras opiniones, incluyendo críticas, y que las mismas no fueran impugnadas o rechazadas, con muchas idas y vueltas, que pudimos sostener.

Mientras nos desarrollábamos en lo académico e institucional, a través de esta actividad en Flacso, mi militancia política continuó. Se creó el Frente Grande (1993) y yo ya no era joven (con 34 años no era parte de la juventud), pero me dediqué a trabajar sobre la programática juvenil en los equipos técnicos. Al año siguiente se convocó a una reforma de la Constitución Nacional y desde el Frente Grande de la capital me designan como asesor en la Convención. Allí, tomo la temática de «nuevos derechos» y, si bien el tema juventud como tal no estaba habilitado a tratamiento, soy quien atiende a muy diversas delegaciones y representantes de organizaciones juveniles y que trabajan con jóvenes, para recibir sus proyectos y cambiar ideas alrededor de ellos. Un proceso muy enriquecedor y que me permitió ampliar redes. Más tarde, en el 98, la Federación Universitaria de la UBA crea su «Casa de los estudiantes» y participamos de ella, en el diseño y en actividades. En cierta medida pusimos a prueba algunas ideas piloto, como casa de la juventud. Luego, cuando el Frente Grande hace alianza con el radicalismo y triunfan en las elecciones del año 99, los radicales asumen la Dirección Nacional de la Juventud y me ofrecen el área de investigaciones y estudio.

En la Dirección Nacional de Juventud reorganizamos el centro de documentación e información; compramos libros para su biblioteca por primera vez en años; hicimos un directorio de investigadores e investigaciones; digitalizamos los envíos de sus productos, de sus boletines mensuales; y lanzamos una revista (Mayo), eso en lo específico del área. Además, trabajamos en lo que refería a casas de juventud y su dinámica interna para asegurarnos que fueran genuinamente participativas. En cuanto al boletín, lo reconfiguramos; sus contenidos incluían un tema central, con columnas de expertos, pero también artículos sobre organizaciones juveniles, becas, ofertas para jóvenes y una parte - pero solo una parte - era para los programas de la Dirección. Era un boletín de juventudes. No fue sencillo escapar al «ombliguismo» de centrarse en la institución.

Como novedad, diseñamos una «hoja mural» (ahora son más frecuentes) con datos de las juventudes que era una matriz muy completa, federal, donde en columnas podías ver las cifras diferenciadas según provincias en temas de educación, salud, empleo en jóvenes; en fin, distin- 
tos temas y según sexo, además. Es decir, básicamente, tenías una foto que era un diagnóstico de las juventudes del país. Enfocabas una provincia u otra y rápidamente podías ver cuál era la situación en los diferentes temas. Era una especie de afiche; se podía pegar en cualquier lugar y tuvo gran impacto; nos la pedían muchas instituciones y organizaciones con el fin de visibilizar la situación de los jóvenes y también para recalcar la importancia de contar con esos datos para desarrollar una política y crear un área de juventud. Era un producto sencillo pero valioso que enviamos a diputados y senadores que trabajaban temas de juventud; también a todos los ministerios que habían colaborado aportando cifras, lo cual nos permitió generar vínculos en cada uno de ellos. Aprendimos con este producto y con el boletín a establecer relaciones y diálogos dentro del Gobierno, lo cual nos facilitó, por ejemplo, el organizar una jornada interinstitucional muy necesaria. Convocamos a que cada Ministerio expusiera sus programas y actividades destinadas a jóvenes o que los tuviera por principales usuarios o beneficiarios, con la sorpresa que, cuando organizamos los paneles (por ejemplo en temas de consumos problemáticos o de salud, trabajo, o desarrollo social), nos dábamos cuenta que había desconocimiento del trabajo del otro; cada uno trabajaba el mismo tema pero con conceptos diferentes; se solapaban algunos territorios y otros quedaban vacíos. Ya te imaginas. Eso pasa cuando no hay coordinación de políticas. Pero hacerlo visible, con la participación de todos los sectores del gobierno, fue impactante para todos; incluso para los asistentes como público externo, representantes de organizaciones juveniles a los que invitamos para que conocieran la oferta en temas de juventud que tenía el gobierno. Pienso que hicimos cosas que valió la pena, hasta que se dio la salida del Frente Grande del gobierno en el mes de septiembre del año 20oo. Yo me organizo, dejo las cosas en otras manos y me voy en abril de 2001.

Entonces, concurso en el Ministerio de Educación de la Nación en términos de experto y no ya como funcionario político, pues iban a armar un programa llamado Escuela para jóvenes; les pareció interesante mi perspectiva y pasé a formar parte del equipo que diseñó y puso en marcha los Centros de Actividades Juveniles en el año 2001. A finales de ese año se presenta la gran crisis de Argentina; días antes renuncié al ministerio; la situación era demasiado complicada y claramente el fin de un ciclo. Seguí en Flacso y tuve la oportunidad de acompañar muy de cerca la experiencia de las políticas de juventud de la ciudad de Rosario, primero, y de la provincia de Santa Fe, más tarde, ya desde la Fundación Ebert. Los gobiernos socialistas nos invitaron para que los orientáramos en el trabajo en temas de juventud. Pudimos aportar al diseño y evaluación de sus programas, debatir los temas de juventud y capacitar funcionarios. ${ }^{12}$

${ }_{12}$ El trabajo del autor durante esos años puede seguirse en Balardini (2000b, 2000c, 2005). 


\section{De Flacso a Clacso y la FES}

C. F.: ¿Podrías hablarme de cómo te involucraste en Clacso, cómo creásteis el grupo de trabajo sobre juventud y cómo entrásteis en contacto con el resto de «juvenólogos» latinoamericanos?

S. B.: Allá por el año 1995 hubo acercamientos entre Flacso y Clacso para ver qué tenían ambas instituciones en temas de juventud. Nos enteramos que Clacso iba a realizar un encuentro en Chile sobre el tema y nos sumamos. En ese momento se plantea la reconstrucción del grupo de trabajo, que tiempo atrás había coordinado Dina Krauskopf (con quien inmediatamente de conocernos sintonizamos en la importancia de la participación juvenil) y nos proponen asumir la coordinación del grupo — desde Flacso- de la cual me encargo desde 1997 al 2003. Reconstruimos el grupo, hicimos varias reuniones anuales, un libro, sumamos investigadores y países. Se establecieron vínculos institucionales entre Flacso, Clacso y la OIJ. También pudimos intercambiar con investigadores de Europa, en donde nos encontramos.

En el año 2003 -también desde Flacso- alentamos ciertas discusiones relacionadas a las políticas nacionales de juventud. Con el comienzo del gobierno de Néstor Kirchner se presenta la necesidad de iniciar una etapa nueva en cuanto a políticas y organizamos unas jornadas con diputados interesados en la posible sanción de una ley de juventud y en ella participan varias instituciones. Sin que me lo esperara, en medio de ese proceso recibo el ofrecimiento de la Fundación [Friedrich] Ebert (FES) ${ }^{13}$-interesada en el desarrollo de políticas públicas y el trabajo en juventudes- de sumarme a su plantilla a fin de desarrollar temas de políticas de juventud; decisión difícil para mí, porque mi historia había sido la de Flacso. Pero, al mismo tiempo, el ofrecimiento de la fundación era muy atractivo por los recursos que destinaba al tema.

Antes de tomar una decisión, lo conversé con René Bendit, con el equipo de juventud y con la directora en ese momento de Flacso, Guillermina Tiramonti. Me parecía que debía hacerlo así por respeto a la institución que me cobijó tantos años y a las personas que me habían acompañado hasta allí. A todos les planteé la oferta que había recibido y tuve su apoyo; me dijeron que debía aceptarla, pero que no me fuera por completo de Flacso sino que buscara articular acciones. Empiezo en la FES en el año 2004 instalando los temas en políticas de juventud que eran interés de la fundación y creamos un grupo de trabajo sobre juventud para gobiernos locales. Organizamos reuniones en Flacso y en ciudades como Rosario, Mendoza, Córdoba, Mar

13 Fundación alemana vinculada al partido socialdemócrata, cuyo nombre proviene del primer presidente alemán elegido democráticamente. https://www.fes-argentina.org 
del Plata y Tierra de Fuego. Ampliamos la unidad de juventud de las Mercociudades ${ }^{14}$ y empezamos a trabajar en términos regionales.

Asimismo, cuando en 2007 en la Provincia de Santa Fe el socialismo asume el gobierno, comenzamos a colaborar intensamente en la construcción de un Gabinete Joven provincial, además de continuar el apoyo al Centro de la Juventud de la ciudad de Rosario. En este proceso pudimos traer a Héctor Castillo, Dina Krauskopf, Oscar Dávila, José Antonio Pérez Islas, Humberto Abaunza y otros especialistas y grandes amigos a las Conferencias Anuales de Políticas Públicas de Juventudes. Aprovechamos sus visitas para reuniones de intercambio en el Centro de la Juventud con el equipo del Gabinete Joven y en las conferencias, a la cuales van las comunas, los departamentos, los municipios, con sus responsables de juventud o sus equipos técnicos para exponer ideas y sobre el trabajo de las organizaciones juveniles; un proceso participativo interesante y productivo. El trabajo en la FES me llevó a dedicar más tiempo a la gestión de proyectos relacionados a la política pública y a la formación de juventudes políticas, y menos a la investigación; sin embargo, siempre proyectando hacia el futuro de las juventudes. Finalmente, en 2016, tuve la oportunidad de lanzar en la Universidad Nacional de Hurlingham (Unahur) una materia sobre culturas juveniles.

Así que ya ves, ahí vamos de nuevo. ${ }^{15}$

\section{Listado de referencias}

Balardini, S. (200oa). Córdoba, 'Cordobazo' i després. Mutacions del moviment juvenil a l'Argentina. En C. Feixa, \& J. R. Saura (Eds.), Joves entre dos móns. Moviments juvenils a Europa $i$ a l'América Llatina. II Fórum d'Estudis sobre la Joventut. Secretaria General de Joventut; UdL.

Balardini, S. (20oob). (Comp.) La participación social y politica de los jóvenes en el horizonte del nuevo siglo. Clacso. http://168.96.200.17/ar/libros/cyg/juventud/prologo.pdf

Balardini, S. (2000c). Jóvenes e identidad en el ciberespacio. Nómadas, 12, 100-111.

Balardini, S. (2002). Córdoba, "Cordobazo" y después. Mutaciones del movimiento juvenil en Argentina. En C. Feixa, J. R. Saura, \& C. Costa (Eds.), Movimientos Juveniles: de la globalización a la antiglobalización (pp. 37-58). Ariel.

\footnotetext{
14 Las Mercociudades son ciudades que se agrupan en red en el marco de los países del Mercosur.

15 La entrevista se acaba abruptamente por falta de tiempo, aunque queda pendiente el relato actualizado de su trabajo sobre juventud en la fundación y la situación presente de la juventud argentina.
} 
Balardini, S. (2004). O seculo XX e as geraçoes jovens da Argentina. En A. Caccia-Bava, C. Feixa, \& Y. González (Eds.), Jovens na America Latina (pp. 15-62). Escrituras.

Balardini, S. (2005). ¿Qué hay de nuevo, viejo? Una mirada sobre los cambios en la participación juvenil. Nueva Sociedad, 200, 96-107.

Balardini, S. (2013). El siglo XX y las generaciones jóvenes de Argentina. En Y. González, \& C. Feixa (Eds.), La construcción histórica de la juventud en América Latina: bohemios, rockanroleros \& revolucionarios (pp. 269-222). Cuarto Propio.

Balardini, S., \& Hermo, J. P. (1997). La cocina de una investigación. JOVENes. Revista de Estudios sobre Juventud, 3, 1-11.

Caccia-Bava, A., Feixa, C., \& González, Y. (Eds.) (2004). Jovens na America Latina. Escrituras.

Feixa, C., \& Saura, J. R. (Eds.) (200o). Joves entre dos móns. Moviments juvenils a Europa i América Llatina. Secretaria General de Joventut; UdL.

Feixa, C., \& Urteaga, M. (2019). Does it exist an Iberoamerican "Youthology"? A conversation. Youth and Globalization, 1(2), 307-314. https://doi.org/10.1163/25895745-00102006

Feixa, C., Saura, J. R., \& Costa, C. (Eds.) (2002). Movimientos Juveniles: de la globalización a la antiglobalización. Ariel.

García-Cancini, N., \& Urteaga Castro-Pozo, M. (2017). Maritza Urteaga y Néstor García-Canclini conversan sobre la juventud en las ciencias sociales: delincuentes, consumidores, migrantes o actores alternativos. Metamorfosis, 6, 2-27.

González, Y., \& Feixa, C. (Eds.) (2013). La construcción histórica de la juventud en América Latina: bohemios, rockanroleros \& revolucionarios. Cuarto Propio.

Martín-Barbero, J., \& Feixa, C. (2018). Jesús Martín-Barbero y Carles Feixa conversan sobre comunicación, juventud y memoria: «Todo lo que sabemos lo sabemos entre todos». Metamorfosis, 8, 2-28.

Pérez-Islas, J. A., \& Urteaga Castro-Pozo, M. (2019). José Antonio Pérez-Islas y Maritza Urteaga conversan sobre juventud. Metamorfosis, 10, 2-27.

Reguillo, R., Feixa, C., \& Ballesté, E. (2018). Rossana Reguillo, Carles Feixa y Eduard Ballesté conversan sobre paisajes juveniles sumergidos, emergentes e insurrectos. Metamorfosis, 9, 2-26. Sáez, J. (1988). El Frente de Juventudes: política de juventud en la España de postguerra 1937-1960. Siglo XXI. 